\title{
الوقف عند الإمام النووي الشافعي ومدى مو افقته لتنمية الوقف في إندونيسيا
}

\section{Irsan}

Program Studi Ekonomi Syariah

Institut Agama Islam Tazkia Bogor

Irsan286@gmail.com

\section{Erwandi Tarmizi}

Program Studi Ekonomi Syariah

Institut Agama Islam Tazkia Bogor

info@erwanditarmizi.com

\section{Hendri Tanjung}

Program Studi Ekonomi Syariah

Universitas Ibnu Khaldun Bogor

hendri.tanjung@gmail.com

\section{ملخص البحث}

ههدف هذا البحث العلمي إلى معرفة مدى موافقة الوقف عند الإمام النووي الشافعي رحمه الله لتنمية الوقف في إندونيسيا. ومنهج هذا البحث هو المنهج التحليلي والمنهج المقارن. المنهج التحليلي هو بأن يحلل الباحث فقه الوقف عند الإمام النووي مستعينا بما في كتاب روضة الطالبين ومنهاج الطالبين, والمنهاج في شرح صحيح مسلم, وفتاوى الإمام النووي

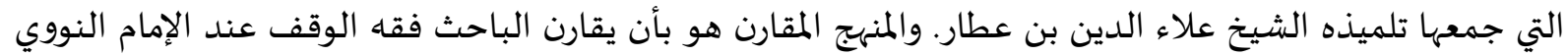
وقانون الوقف رقم 41 عام 2004 مقارنة تحليلية حتى يصل إلى مدى الموافقة بينهما. وخلص هذا البحث بـ إلى أن أن للإمام

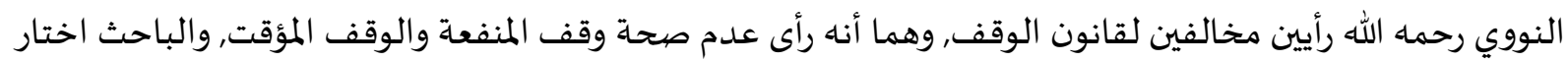
أن الراجح صحة وقف المنفعة والوقف المؤقت لقوة مستنداتهما. وخلص هذا البحث إلى أن للإمام النووي رحماه الله رأيا

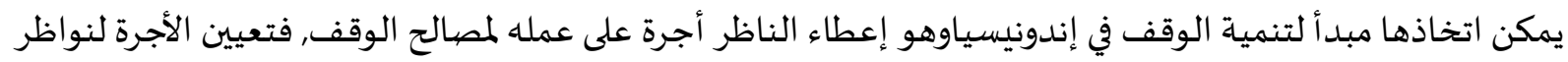
الأوقاف يمكن أن يكون باعثا في انضباط نواظر الأوقاف في إندونيسيا, وأداء توليتهم لها, وفي إكثار الأوقاف الاستيثمارياءة

$$
\text { كلمات رئيسية: تنمية الوقفة هيقة تنمية الوقف. }
$$

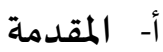

إن من أعظم الصدقات أجرا وفضلا الأوقاف بأشكالها المتنوعة, من مصاحف وكتب علمية, ومن أراض وعقارات,

ودراهم ودنانير, وبساتين وآبار وغير ذلك.وبعد الاطلاع على البحوث العلمية المتعلقة بالوقف يرغب الباحث في كتابة البحث 
العلمي عن أحكام الوقف عند الإمام النووي الشافعي رحمه الله ومدى موافقته لتنمية الوقف في إندونيسيا,علما بأن مذهب أغلب مسلمي إندونيسيا هو المذهب الشافعي (محمد خضري, 7:2018), وحسب علم الباحث أنه لم يكتب أحد بحثا علميا في هذا الموضوع, فاختار الباحث أن يكتب البحث بعنوان ((الوقف عند الإمام النووي الشافعي ومدى موافقته لتنمية الوقف في إندونيسيا))مستعينا بالله سبحانه وتعالى.والمراد بالوقف عند الإمام النووي الشافعي هو ما تضمنه مؤلفات الإمام النووي الشافعي من فقه الوقف سواء كان من اختياراته أو ترجيحاته. ومن أسباب اختيار هذا الموضوعكون مذهب أغلب مسلمي إندونيسيا المذهب الشافعي, وحرص الباحث على الاستفادة من آراء الإمام النووي الشافعي في فقه الوقف لتنمية الوقف في إندونيسيا. وأسباب اختيار الباحث فقه الوقف عند الإمام النووي الشافعي دون السادة الشافعية الآخرين هي أن من أدوار المذهب الشافعي دور التأسيس, ودور النقل ودور التحرير,ودور التحرير هو دور التحقيق والتهذيب حيث يهذب المذهب في هذا الدور من الآراء المرجوحة. والإمام النووي الشافعي رحمه الله معروف بمحقق ومهذب المذهب. والإمام النووي الشافعي رحمه الله أدق السادة الشافعية في النظر وأتقهم في تنقيح المذهب.ولم يكن أحد من الباحثين حسب علم الباحث يكتب بحثا علميا تحت هذا الموضوع. وإشكالية هذا البحث تتكون من أسئلة: ما هي أهم أحكام الوقف عند الإمام النووي الشافعي رحمه الله؟ وهل للإمام النووي الشافعي رحمه الله آراء مخالفةلقانون الوقف رقم 41 عام 2004؟ وهل للإمام النووي الشافعي رحمه الله آراء يمكن اتخاذها مبدأ لتنمية الوقف في إندونيسيا؟ انطلاقا من ذطر إشكالية البحث, فأهداف هذا البحث هي: تحليل أهم أحكام الوقف عند الإمام النووي الشافعي رحمه الله وترجيحاته فيما اختلف الشافعية فيه, وتحليل مدى موافقة أحكام الوقف عند الإمام النووي الشافعي رحماه الله لتنمية الوقف في إندونيسيا, ودراسة وتحليل آراء الإمام النووي الشافعي رحمه الله التي يمكن اتخاذها مبدأ لتنمية الوقف في إندونيسيا. وترجع أهمية هذا الموضوع إلى كون الإمام النووي من السادة الشافعية, والمذهب الشافعي يتمذهب باه أغلب مسلمي إندونيسيا. وكون الوقف من أهم أنواع الصدقات النافعة للإسلام والمسلمين والدولة.وتناول هذا البحث دراسـة تحليلية لفقه الوقف عند الإمام النووي الشافعي, وذلك بدراسة مؤلفات الإمام النووي التي تتناول فقه الوقف وتحليل مدى موافقته لقانون الوقف رقم 41 عام 2004. 
نظرا إلى طبيعة موضوع هذا البحث, فإن المنهج الملائم الذي يرى الباحث استخدامه في كتابة هذا البحث هو المنهج التحليلي والمنهج المقارن.والمنهج التحليلي هو بأن يحلل الباحث فقه الوقف عند الإمام النووي مستعينا بما في كتاب روضة الطالبين ومنهاج الطالبين, والمنهاج في شرح صحيح مسلم, وفتاوى الإمام النووي التي جمعها تلميذه الشيخ علاء الدين بن عطار. والمنهج المقارن هو بأن يقارن الباحث فقه الوقف عند الإمام النووي وقانون الوقف رقم 41 عام 2004 مقارنة تحليلية حتى يصل إلى مدى الموافقة بينهما.

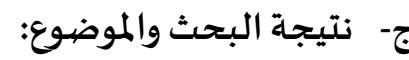
1. 1 التعريف بقانون الوقف رقم 41 عام 2004 قانون الوقف رقم 41 عام 2004هو قانون أصدرته الحكومية الإندونيسية لتنظيم وتطوير الأوقاف بأنواعها المتعددة. لإصدار هذا القانون سببان أسـاسيان:(1) في تطبيق الوقف فرص لتنمية اقتصاد المجتمع, مثل تطبيق وقف النقود, وفي 28 صفر 1423هـ الموافق 11 مايو 2002 أفتى مجلس علماء إندونيسيا بجواز وقف النقود. فأرادت الحكومة تحقيق وتطوير هذه الفرص (وزارة الشؤون الدينية, 9:2005).(2) تطبيقات الأوقاف لم تكن منظمة وفعالة بشكل كامل, والدليل على ذلك أنها يوجد من أصول الأوقاف ما لا تتم صيانتها بشكل جيد, بل تتحول إلى طرف ثالث بمخالفة القانون (137:2020, Nuansa Aulia فريق التحرير). ولإصدار هذا قانون رقم 41 عام 2004 أغراض:لتنظيم شؤون الأوقاف, ولتوسيع نطاق موضوع الوقف, ولتوسيع نطاق استخدام الوقف, ولتأمين الأوقاف من تدخلات الطرف الثالث الذي يضر بها, ولإنشاء هيئة الأوقاف الإندونيسية. وينتاول قانون الوقف رقم 41 عام 2004 تعريف الوقف وشروطه وأنواعاء, وتعريف الواقف وشروطه, تعريف الناظر وشروطه ووظائفه, والموقوف عليه, وطريقة التسجيل والإجراءات, وأغراض الوقف, والوصية بالوقف, والوقف النقدي, وإعلان الوقف, وإدارة الوقف وتنميته, واستبدال الوقف والأحكام المتعلقة به, والتعريف بهيئة الأوقاف ووظائفها, وفصل التنازع, والأحكام الجنائية والعقوبة الإدارية, والرقابة على الأوقاف. 
التنمية لغة مصددر نمّ ينمّي تنمياة, والتنمية جعل شيء ينمو أي جعله يرتفع ويزداد(ابن منظور: 15\342).وتنمية

الوقف اصطلاحا هي الإجراءات المستدامة والمنسقة التي يتخذها صناع السياسية والجماعات المشتركة, والتي تساهم في تعزيز مستوى منفعة الوقف وتطبيقاته (محمد أفدي, 25:2017). فيعرف نمو الوقف وتطوره إذا تمت إدارته على شكل جيد, وإذا انتفع الناس انتفاعا كثيرا, وإذا ازدادت تطبيقاته. فتنمية الوقف تكون خلال تحقيق ثلاثة أمور:تنظيماه وإدارته على شكل جيد, وانتفاع الناس باه, وازدياد تطبيقات الوقف. 3. أهم مباحث الوقف عند الإمام النووي رحمه الله.

وتعريف الوقف عند الإمام النووي رحماه الله هو تحبيس كل عين معينة مملوكة ملكا يقبل النقل وتسبيل المنفعة المباحة مع بقاء العين(النووي: 5\314).وقد اشتمل التعريفعلنخمسة أمور اوهي:تحبيس كل عين معينة:وخرج بهذا تحبيس عين غير معينة وتحبيس المنافع, مملوكة ملكا يقبل النقل: وعلهذالايصحّأنيقفالإنسانشيئًا لايملكه، وهو ليس بوكيل في إنشاء الوقف, لأنالوقفنقللملكيةالموقوفمنحوزةالمالك.وتسبيل المنفعة المباحاة: خرج بهذا تسبيل المنفعة المحرمة.مع بقاء العين: خرج بهذا كل ما ينتفعباستهلاكها, فلا تبقى العين. واستند هذا التعريف إلى قول النبي صلى الله عليه وسلم لعمر رضي الله عنه حين أصاب أرضا بخيبر: ((إن شئت حبست أصلها، وتصدقت بها))(البخاري: 12\). ووجه الاستناد: حبس عمر رضي الله عنه أرضا بخيبر, وهي عين معينة, وتصدق بثمرها مع بقاء الأرض. أركان الوقف عند الإمام النووي رحماه الله أربعة (النووي:5\314-363):

أ) الركن الأول هو الواقف. يشترط كونه صحيح العبارة, أهلا للتبرع, فيخرج عنه الصغير والمجنون والمغنى عليه والمبرسم الذي يهذي، فلا يصح وقفهم كسائر التصرفات.واستند الركن الأول إلى قول الله تعالى: لهَوَلَا تُوُتُوُواً

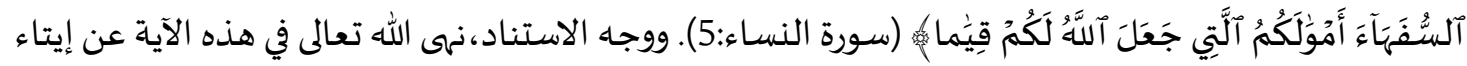
السفهاء الأموال, لأن السفهاء هم من لا رشد لهم, وهم الصغير, والمجنون والمغمى عليه, فلا يصح منهم سائر التصرفات في الأموال, ومهنا الوقف.

ب) الركن الثاني هو الموقوف. وهو كل عين معينة مملوكة ملكا يقبل النقل يحصل منها فائدة أو منفعة تستأجر لها. احترز بالعين حق المنفعة، وعن الوقف الملتزم في الذمة، وبالمعينة، عن وقف أحد أراضيه، وبالمملوكة عما لا 
يملّكُ، وبقبول النقل، عن المال المرهون والملاهي. والمراد بالفائدة هو الثمرة واللبن ونحوهما، وبالمنفعة هو السكنى واللبس ونحوهما, وتستأجر لها، احترازا من الطعام ونحوه.واستند اشتراط الموقوف كونه عينا إلى قول النبي صلى الله عليه وسلم: ((إن شئت حبست أصلها، وتصدقت بها))(مسلم: 3\1255).ووجه الاستناد، حبس عمر رضي الله عنه أرضا بخيبر, والأرض عين, فظاهر الحديث يدل على تحبيس عين معينة, وليس تحبيس المنفعة. استناد اشتراط الموقوف كونه مملوكا ملكا يقبل النقل: استند اشتراط الموقوف كونه مملوكا ملكا يقبل النقل إلى مقتضى الوقف, وهو نقل الملكية. ووجاه الاستنادأن الوقف نقل الملكياة, فلا ينعقد الوقف إلا في ما يقبل النقل. ج) الركن الثالهو الموقوف عليه. وهو قسمان (النووي:517): 1) أن يكون شخصا معينا، أو جماعة معينين، فشرطه أن يمكن تمليكا، فيجوز الوقف على ذمي من مسلم وذمي، كما تجوز الوصية له، ولا يصح الوقف على الحربي والمرتدّ (النووي, 1426ه:319). واستند جواز

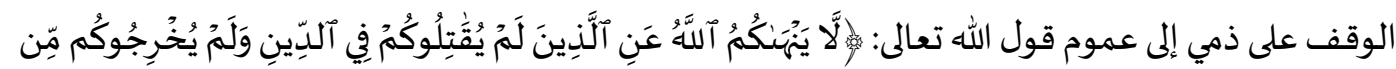

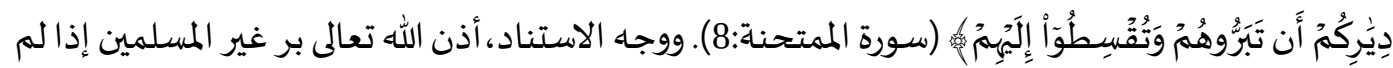
يكونوا أهل حرب لنا, والوقف عليهم نوع من البر, فاقتضى جواز الوقف عليهم, والذمي منهم. واستند جواز الوقف من ذمي إلى أن الأصل في المعاملات الإباحة.ووجاه الاستناد،صح الوقف الذمي لأن الوقف من المعاملات المالية.

واستناد عدم صحة الوقف على الحربي، استند عدم صحة الوقف على الحربي إلى قول الله تعالى:

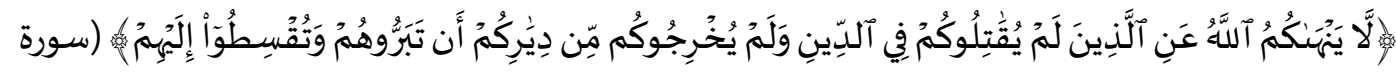
الممتحنة:8). ووجه الاستناد، أخبر الله تعالى بأنه لا ينهى بر غير المسلمين إذا لم يكونوا أهل حرب لنا, فمفهوم المخالفة هو أن الله ينهى عن البر لهم إذا كانوا أهل حرب لنا, فلا يصح الوقف عليهم.استناد عدم صحة الوقف على المرتد،استند عدم صحة الوقف على المرتد إلى القياس على الوقف على الحربي. ووجه الاستاد، لا يصح الوقف على المرتد كما لا يصح الوقف على الحربي بجمع أنهما يستحقان القتل, فلا دوام لهما. الوقف على غير معين، كالفقراء والمساكين، وهذا يسمى وقفا على الجهاة، لأن الواقف يقصد جهة الفقر والمسكنة، لا شخصا بعينه، فينظر في الجهاة، إن كانت على المعصية، كعمارة الكنيسة وقناديلها وحصرها، 
وكتب التوراة والإنجيل، لم يصح، سواء وقفه مسلم أو ذمي، فنبطله إذا ترافعوا إليا. أما ما وقفوه قبل المبعث على كنائسهم القديمة، فنقره حيث نقر الكنائس (النووي:5173).استناد منع الوقف على جهة

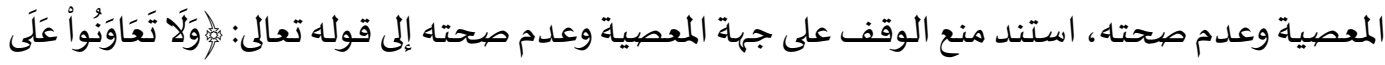

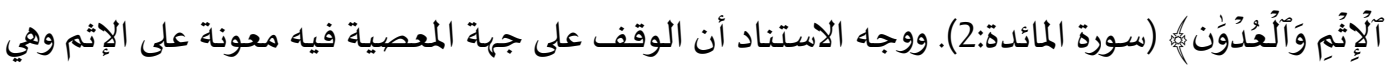
محرمة، فلا يجوز الوقف على جهة المعصية ولا يصح. د- الركن الرابع هو الصيغة. فلا يصح الوقف إلا بلفظ. (النووي, 1425هـ:168-170).واستند الركن الرابع إلى قوله

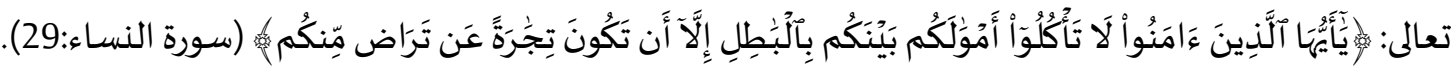
ووجه الاستناد، نهى الله تعالى في هذه الآية عن أكل الأموال بين المؤمنين بالباطل. واستثنى منه أكل الأموال عن طريق التجارة عن التراضي, والتعراضي بين المتعاقدين إنما يعرف باللفظ. وكذا في الوقف, لا يعرف رضا الواقف إلا باللفظ.واللفظ نوعان:أولا ، اللفظ الصريح, مثل وقف هذه الأرض, أو أرضي موقوفة, أو التسبيل والتحبيس من الألفاظ الصريحة, مثل سبلت هذه الأرض, أو حبست هذه الأرض.ثانيا ، اللفظ غير صريح, مثل تصددق بكذا, أو تبرعت بكذا. (النووي:322\3).

$$
\text { وشروط صحة الوقف عند الإمام النووي رحماه الله أربعة (النووي:5\322-331): }
$$

الشرط الأولهوالتأبيد. فالوقف لا يصح إلا إذا كان مؤبدا, فلا يجوز تأقيته بمدة معينة, لو قال رجل وقف هذه الأرض شهرا, لا يصح, أو قال وقف هذه الأرض سنة, لا يصح. وسيأتي استناد هذا الشرط في المبحث الثالث. ب) الشرط الثاني هو التنجيز. وهو بأن يكون منجزا في الحال غير معلق بأي شرط ولا مضاف إلى المستقبل.واستند الشرط الثاني إلى أن مقتضى الوقف نقل الملك حال التبايع. ووجه الاستنادأن الوقف إذا علق على شرط أو مضاف إلى المستقبل لا يترتب عليه أثره وهو انتقال الملكية في الحال. ج) الشرط الثالث هو الإلزام. فلو وقف بشرط الخيار، أو قال: وقفت بشرط أني أبيعا،، أو أرجع فيه متى شئت فباطل. واستند الشرط الثالث إلى القياس على الهبة. ووجه الاستنادأن الهبة إزالة ملك للموهوب لها, فلا خيار فيها, وكذلك الوقف, الوقف إزالة ملك لله تعالى، فلا خيار فيه (ابن قاضي شهبة:22) 
د) الشرط الرابع هو بيان المصرف. فلو قال: وقفت هذا واقتصر عليه، فالوقف باطل, كقوله: بعت داري بعشرة أو وهبتها، ولم يقل لمن، ولأنه لو قال: وقفت على جماعة، لم يصح لجهاله المصرف. فإذا لم يذكر المصرف فأولى أن لا يصح. واستند الشرط الرابع إلى القياس على عدم صحة الوقف بقول الواقف: "وقفت على جماعة" (الأنصاري:265\). ووجاء الاستناد، إذا كان الوقف بقول الواقف: "وقفت على جماعة" لا يصح, فمن باب أولى أن لا يصح إذا لم يذكر المصرف. المراد بشروط الواقف هي الشروط التي شرطها الواقف عند إنشاء الوقف, فيرعى شرط الواقف في الأقدار، وصفات المستحقين، وزمن الاستحقاق. فإذا وقف على أولاده، وشرط التسوية بين الذكر والأنثى، أو تفضيل أحدهما، اتبع شرطه. وكذا الوقف على العلماء بشرط كونهم على مذهب فلان، أو على الفقراء بشرط الغربة، أو الشيخوخة اتبع.(النووي: 11 16-67-67), والأصل في شروط الواقف الصحة والجواز, إلا شرطا أحل حراما أو حرم حلالا. واستنادأن الأصل في شروط الواقف الصحة والجواز هو قاعدة الأصل في المعاملات الإباحة إلا ما منعه الدليل. ووجه الاستنادأن الوقف نوع من المعاملات المالية, فالأصل فيه وفيما شرطه الواقف الصحة إلا ما منعه الدليل. وأما ناظر الوقف هو من قام بتولية الوقف, ويراعى في ناظر الوقف أمور تالية:أولا، صلاحية الناظر لشغل التولية, وهي تكون على صفتين:الأمانة, وهي العدالة, والعدالة ضد الفسق. والكفاية في التصرف, فيشترط أن يكون الناظر بالغا عاقلا رشيداثانيا ، وظيفة الناظر, وهيالعمارة, والإجارة, وتحصيل الغلة, وقسمتها على المستحقين, وحفظ الأصهول والغلات على الاحتياط. هذه الوظائف عند الإطلاق, ويجوز أن ينصب الواقف ناظرا لبعض الأمور دون بعض، بأن يجعل إلى واحد العمارة، وتحُصيل الغلة، والى آخر حفظها، وقسمتها على المستحقين، أو يشرط لواحد الحفظ، واليد، ولآخر التصرف (النووي:347>348-3). وفي استبدال الوقفرأى الإمام النووي رحمه الله أن لتعطل الوقف واختلال منافعه سببين (النووي:594). السبب الأول أن يحصل التعطل بسبب مضمون، مثل أن أتلف شخص الوقف سواء كان عمدا أو بغير عمد, وفي هذه الحالة على المتلف قيمتاه, ويشترى بهذه القيمة مثل ما أتلفه, ويكون وقفا (الرافعب6\294).والسبب الثاني أن يحصل التعطل بسبب غير مضمون, مثل تلف الوقف بسبب الآفات الساموية, فإن لم يبق شيء منه ينتفع به، فقد فات الوقف, 
وإن بقي، كشجرة جفت، أو قلعتها الريح، فلا ينقطع الوقف, فيباع ما بقي لتعذر الانتفاع, ويشترى به شجرة، أو شقص شجرة من جنسها، لتكون وقفا (النووي, 1426هـ:322). الإمام النووي رحمه الله رأى عدم جواز استبدال الوقف إلا إذا تعطل الوقف, فلا بد أن يراعى مقصود الواقف حسب ما أمكن, قال الإمام النووي رحماء الله: ثم المسجد المعطل في الموضع الخراب إن لم يخف من أهل الفساد نقضها لم ينقض وإن خيف، نقض وحفظ.

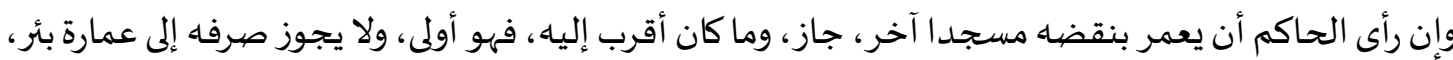

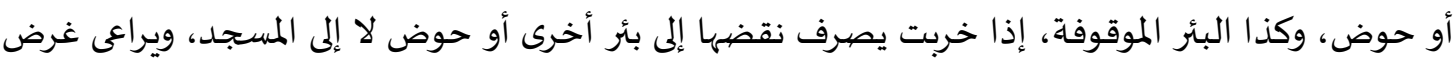

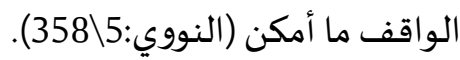

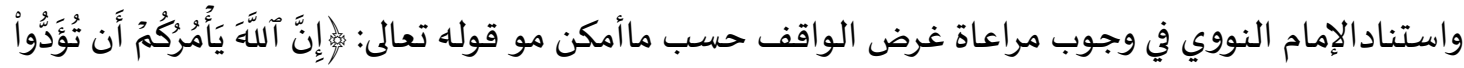

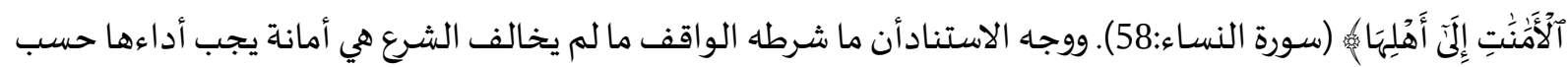

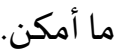

\section{4. أحكام الوقف عند الإمام النووي المخالفة لقانون الوقف رقم 41 عام 2004 دراسة تحليلية} وبعد أن استقرأ الباحث فقه الوقف في كتب الإمام النووي رحمه الله, وجد الباحث رأيين للإمام النووي مخالفين لقانون الوقف, وهما في حكم وقف المنفعة وحكم الوقف المؤقت. وقدقرر قانون الوقف رقم 41 عام 2004 صحة وقف العين ووقف المنفعاة, وقد نص في المادة 16 البند 3 على صحة وقف المنفعة, مثل وقف حقوق الملكية الفكرية.استند قانون الوقف رقم 41 عام 2004, المادة 16 البند 3 إلى حديث عمر رضي الله عنه حين أصاب أرضا بخيبر, قال له النبي صلى الله عليه وسلم: ((إن شئت حبست أصلها، وتصدقت بها)) (البخاري: 12\). ووجه الاستنادهوالحديث أصل في مشروعية الوقف, وليس في الحديث نفي لعدم صحة وقف المنفعة, العين مال والمنفعة مال, فيصح وقف المنفعة. واستند قانون الوقف رقم 41 عام 2004, المادة 16 البند 3 إلى عدم الفرق بين العين والمنفعة. ووجاه الاستناد، أن المقصود من الوقف المنفعة, فما داما المقصود من الوقف هو المنفعة, فيصح وقف المنفعة.واستند قانون الوقف رقم 41 عام 2004, المادة 16 البند 3 إلى عرف الناس. ووجاء الاستنادهوتعارف الناس على أن المنفعة يقابلها عوض, وما يقابلها العوض فله قيمة،, وكل ما له قيمة فهو مال, فالمنفعة مال لا فرق بينها وبين العين, فيصح وقف المنفعة. 
وأما الإمام النووي رحماه الله تعالى اشترط كون الوقف عينا, فخرج به وقف المنافع دون العين. قال الإمام النووي رحمه الله: ((الموقوف، وهو كل عين معينة ...... احترزنا بالعين حق المنفعة)) (النووي:5\314).استند الإمام النووي رحماه الله إلى حديث عمر رضي الله عنه حين أصاب أرضا بخيبر, قال لله النبي صلى الله عليه وسلم: ((إن شئت حبست أصلها، وتصدقت بها)). (البخاري:412). ووجاه الاستناد،حبس عمر رضي الله عنه أرضا بخيبر. والأرض عين, فظاهر الحديث يدل على تحبيس عين معينة, وليس تحبيس المنفعة.ويمكن أن يقال أن هذا الحديث لا يدل على أن الوقف خاص في العين, بل ذكر العين في الحديث وهي أرض, من باب المثال لا من باب الحصر. وبعد ذكر مستندات رأي الإمام النووي وقانون الوقف رقم 41 عام 2004, المادة 16 البند 3 تبين أن الراجح هو نص وقانون الوقف رقم 41 عام 2004, المادة 16 البند 3; لقوة مستندات قانون الوقف رقم 41 عام 2004, المادة 16 البند 3 من المناقشاة, ولمناقشـة مستند رأي الإمام النووي.

$$
\text { وقرر قانون الوقف رقم } 41 \text { عام } 2004 \text { صحة الوقف المؤقت, نص في المادة } 1 \text { البند 1: }
$$

Wakaf adalah perbuatan hukum wakif untuk memisahkan dan/atau menyerahkan sebagian harta benda miliknya untuk dimanfaatkan selamanya atau untuk jangka waktu tertent u sesuai dengan kepentingannya .....

الوقف هو تصرف الواقف لفصل واأو تخل جزء ممتلكاته لينتفع به للأبد أو لفترة زمنية معينة وفقا

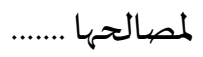

واستند قانون الوقف رقم 41 عام 2004, المادة 1 البند 1 إلى حديث عمر رضي الله عنه حين أصاب أرضا بخيبر, قال له النبي صلى الله عليه وسلم: ((إن شئت حبست أصلها، وتصدقت بها)) (البخاري:4\12). ووجه الاستنادأن النبي صلى الله عليه وسلم أمر بالتحبيس أمرا مطلقا, لا يقيد الأمر بالتأقيت ولا بالتأبيد, فالتحبيس يجوز أن يكون مؤقتا أو مؤبدا.ويمكن أن يقال أن الحديث يدل على أن الوقف مؤبد, حيث قال ابن عمر رضي الله عنه: ((فتصدق بها عمر: أنه لا يباع ولا يوهب، ولا يورث..)), وهذا لا يفهم منه إلا التأبيد (القرطبي:601). ثم يمكن أن يجاب على هذاأن قوله أنه لا يباع ولا يوهب ولا يورث لا يدل على التأبيد, وإنما يدل على أن هذا هو الحكم ما دام وقفا, فإذا انتهت مدة الوقف رجع إلى جواز بيعه, وهبته, وإرثه. وأما التأبيد يستفاد إما بالتصريح, بأن يقول: هذا وقف مؤبد, وإما بغير التصريح كما لو وقف على جها لا تنقطع (الدبيان:16>167). 


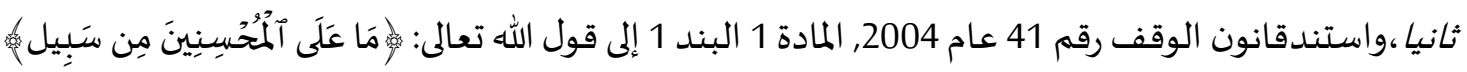
(سورة التوبة:90). ووجه الاستناد،نفى الله تعالى في هذه الآية الطعن في من فعل إحسانا, والوقف المؤقت من الإحسان, فيصح الوقف المؤقت ولا طعن فياهواستندقانون الوقف رقم 41 عام 2004, المادة 1 البند 1 إلى جميع الأدلة الدالة على الإحسان إلى الناس. ووجاه الاستناد: حث الشـارع على الإحسان إلى الناس,والوقف المؤقت من الإحسان. وأما الإمام النووي رحمه الله رأى عدم صحة الوقف المؤقت, قال رحماه الله في شروط صحة الوقف: ((... الأول: التأبيد, ...)) وقال الإمام النووي الشافعي رحمه الله: ((لو قال: وقفت هذا سنة، فالصحيح الذي قطع به الجمهور أن الوقف باطل)) (النووي:325).واستند الإمام النووي رحمه الله إلى رواية ابن عمر أن عمر بن الخطاب رضي الله عنهما,أصاب أرضا بخيبر، فأتى النبي صلى الله عليه وسلم يستأمره فهها، فقال: يا رسول الله إني أصبت أرضًا بخيبر، لم أصب مالًا قط أنفس عندي منه، فما تأمر به؟ قال: ((إِن شئت حبست أصلها، وتصيدقت بها))، فتصبدق بها عمر، أنه لا يباع، ولا يوهب، ولا يورث. ووجاء الاستنادأن قولهفتصدق بها عمر أنه لا يباع ولا يوهب، ولا يورث، هذا لا يفهم منه إلا التأبيد، ولو صيح الوقف مؤقتًا لصح أن يباع, وأن يوهب، وأن يورث (القرطبي:401).ويمكن أن يقال أن قوله أنه لا يباع ولا يوهب ولا يورث لا يدل على التأبيد, وإنما يدل على أن هذا هو الحكم ما دام وقفا, فإذا انتهت مدة الوقف رجع إلى جواز بيعه, وهبته, وإرثه. وأما التأبيد يستفاد إما بالتصريح, وإما بغير التصريح كما لو وقف على جهة لا تنقطع (الدبيان:127\). واستند الإمام النووي رحمه الله إلى قول النبي صلى الله عليه وسلم: ((إذا مات الإنسان انقطع عنه عمله إلا من ثلاثة: إلا من صدقة جارية ...)) (مسلم:3\1255). ووجه الاستناد، أن الوقف صدقة من الصدقات, ولا يكون الوقف صدقة جارية إذا لم يرد باه التأبيد.ويمكن أن يقال أن المراد بالصدقة الجارية في الحديث إما الوقف على التأبيد وإما جريان الثواب بعد الموت ولو لم يكن الوقف على التأبيد (أبو داود: 12\397).وبعد ذكر مستندات رأي الإمام النووي وقانون الوقف رقم 41 عام 2004, المادة 1 البند 1 تبين أن الراجح هو صحة وجوازالوقف الوؤقت, لقوة مستنداته, ولمناقشة مستندات رأي الإمام النووي, والله أعلم. 5. أحكام الوقف عند الإمام النووي يمكن اتخاذها مبدأ لتنمية الوقف في إندونيسيا دراسة تحليلية 
وبعد أن استقرأ الباحث فقه الوقف في كتب الإمام النووي رحمه الله, وجد الباحث رأيا واحدا للإمام النووي يمكن اتخاذه مبدأ لتنمية الوقف في إندونيسيا, وهو إعطاء الناظر أجرة على عمله.رأى الإمام النووي رحماء الله أن لناظر الوقف أجرة على أن يشرط الواقف للناظر شيئا من الغلة, فهو أجرة علمها(النووي:548-349). مستند أن للناظر شيئا من الغلة إذا شرطه الواقف هو أن الأصل في الشروط الصحة, فإذا شرط الواقف شيئا له من الغلة, فهو أجرة عمله إذا كان يساوي أجرة المثل أو أكثر من أجرة المثل,وإذا كان أقل من أجرة المثل فللناظر نصيب زائد من الغلة تكملة أجرة المثل.إن لم يشرط الواقف للناظر شيئا من الغلة. فللناظر أجرة المثل, وهي الأجرة التي جرى عليه عرف أهل البلد, وقدرها أهل الخبرة, ولا يكون أكثر من عشر غلة الوقف, كما نص عليه قانون الوقف رقم 41 عام

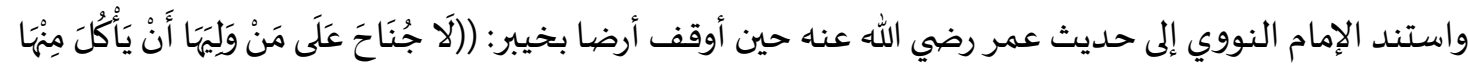
بِالمَعْرُوفِ)) (البخاري:4\12). ووجه الاستنادأنه لا جناح على الناظر أخذ ما يتعارفه الناس بينهم ولا ينسبون فاعله لإفراط فيه ولا تفريط, فذلك أجرة المثل (القتيبي:25).واستند الإمام النووي إل القاعدة "المعروف عرفا كالمشروط شرطا". ووجه الاستنادأن الناس تعارفوا على أن الإنسان إذا عمل لمصلحة الغير يستحق الأجرة,وإذا كانت الأجرة غير معينة,فترجع إلى العرف, وهي أجرة المثل. - مل ويمكن أن يكون إعطاء الناظر أجرة عمله عاملا من عوامل تنمية الوقف استأناسا بالأمور التالية: أ) الأجرة تؤثر على انضباط الموظف. وقد قام YuliansyahM. Diahو,SupardiA. Bakrig, Puput MaretaSari بالبحث عن تأثير الأجرة على انضباط الموظف في عمله في مؤسسة ضيمان جودة التربية بسومطرة الجنوبية, ووصلوا في بحثهم إلى أن الأجرة تؤثر على انضباط

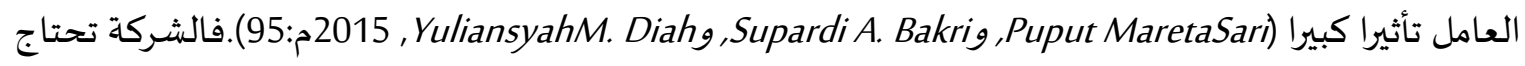
إلى انضباط الموظفين أو انضباط العمل في تنفيذ أنشطتها, حتى تنفذ تلك الأنشطة في الوقت المحدد وبفعالية وكفاءة, وحتى تحققت مصالح الشركة, وتنظيم الوقف كتنظيم الشركاة, يحتاج إلى انضباط الناظر.

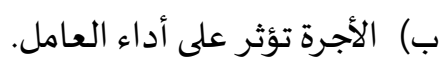


قام بعض الباحثين بالبحث عن مسألة هل الأجرة تؤثر على أداء الموظف. وممن قام بالبحث في هذه المسألة Global (PT.GM) و Gan Arifudin الأجرة يؤثر على أداء الموظف تأثيرا كبيرا. ومنهم Ashadi Mahmud, Ike Ratnasari, قد قاما بالبحث عن تأثير الأجرة على أداء العامل في قسم الإنتاج في شركة Uniplastindolnterbuana Pandaan, ووصلا في بحثهما إلى أن الأجرة يؤثر على أداء الموظف تأثيرا كبيرا (Ashadi Mahmud, Ike Ratnasari, 2020م:77). ومنهم Marianus Subianto, قد قام بالبحث عن تأثير الأجرة على أداء الموظف في شركة Serba Mulia Auto بمنطقة كوتاي الغربية, ووصل في بحثه إلى أن الأجرة يؤثر على أداء الموظف تأثيرا كبيرا. ومن خلال نتائج البحوث المذكورة عرفنا أن الأجرة تؤثر على أداء الموظفين في الشركة تأثيرا كبيرا للحصول على أهدافها وتحقيق مصالحها, وتنظيم الوقف كتنظيم الشركة.وقد قام مركز اللغة والثقافة بجامعة الشريف هداية الله الإسلامية بالبحث عن المسائل المتعلقة بالأوقاف في إندونيسيا, وخلص البحث إلى أن أن 84\% من نواظر الأوقاف في إندونيسيا لا يحصولون على الأجرة, وأن 84\% من نواظر الأوقاف في إندونيسيا لا يركزون على تنظيم الأوقاف, لأنهم مشغولون بمهنهم الخاصة, وأن 77\% من الأوقاف في إندونيسيا هي أوقاف استغلالية, 23\% منها الأوقاف الاستثمارية (رحمت دهلان, 2017م:177). فتعيين الأجرة لنواظر الأوقاف يمكن أن يكون باعثا في انضباط نواظر الأوقاف في إندونيسيا, وأداء توليتهم لها, وفي إكثار الأوقاف الاستثمارية, وهذه هي حقيقة تنمية الوقف. والله أعلم.

1. أهم أحكام الوقف عند الإمام النووي الشافعي: (أ) لا يصح الوقف إلا إذا كان عينا معينة مملوكة ملكا يقبل النقل ويحصل منها الفائدة المباحة، (ب) يشترط في الواقف كونه صحيح العبارة, أهلا للتبرع, (ج) لا يصح الوقف إلا بلفظ, (د) لا يصح الوقف المؤقت، (ه) يشترط في صحة الوقف أن يكون منجزا، (و) الأصل في شروط الواقف الصحة والجواز، (ز) يشترط في الناظر صفة الأمانة والكفاية في التصرف, (ح) رأى الإمام النووي عدم جواز استبدال الوقف إلا إذا تعطل الوقف, فلا بد أن يراعى مقصود الواقف حسب ما أمكن. 
2. آراء الإمام النووي الشافعي رحمه الله المخالفة لقانون الوقف رقم 41 عام 2004: (أ) رأى الإمام النووي رحمه الله عدم صحة وقف المنفعاة, وأما قانون الوقف رقم 41 عام 2004 نص صحة وقف المنفعة. وبعد عرض مستندات كل رأي ومناقشتها, اختار الباحث أن الراجح في هذه المسألة هو صحة وقف المنفعة, لسلامة مستندات قانون الوقف رقم 41 عام 2004, المادة 16 البند 3 من المناقشـة, ولمناقشـة مستند رأي الإمام النووي. (ب) رأى الإمام النووي رحماه الله عدم صحة الوقف المؤقت, وأما قانون الوقف رقم 41 عام 2004 نص صحة الوقف المؤقت. وبعد عرض مستندات كل رأي ومناقشتها, اختار الباحث أن الراجح في هذه المسألة هو صحة الوقف المؤقت, لقوة مستنداتها, ولمناقشة مستندات رأي الإمام النووي. 3. رأي الإمام النووي الذي يمكن اتخاذها مبدأ لتنمية الوقف في إندونيسيا, وهو إعطاء الناظر أجرة على عمله لمصالح الوقف, فتعيين الأجرة لنواظر الأوقاف يمكن أن يكون باعثا في انضباط نواظر الأوقاف في إندونيسيا, وأداء توليتهم لها, وفي إكثار الأوقاف الاستثمارية, وهذه هي حقيقة تنمية الوقف. ابن عطار.فتاوى الإمام النووي.بيروت:دار البشر الإسلامية, 1417هـ. ابن قاضي, شهبة.بلد/ية المحتاج في شرح المنهاج. جدة: دار المنهاج للنشر والتوزيع, بrع اهـ. ابن منظوربلسان العرب.بييروت: دار صادر, 1414هـ. أبو العباس, أحمد.شرح سنن أبي داود. الفيوم: دار الفلاح للبحث العلمي وتحقيق التراث, 1437هـ. أفدي,محمد.Development of Productive Waqf in Indonesia: Potential and Problems, جاكارتا: وزارة المالية

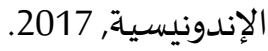

$$
\text { الأنصاري, زكريا.أسنى المطالب في شرح روض الطالب. بدوناسمالمدينة: دار الكتاب الإسلامي, بدونالسنة. }
$$


خُضري، محمد."Al-Qaulul Mukhtar Linnawawi Sebagai Pendapat Alternatif Muslim Nusantara, Vol. XII, No. 1, Juni مجلة الفقه الإسلامي, 2018 الدبيان , دبيان بن محمد./لمعاملات /لمالية أصالة ومعاصرة. بدوناسمالمدينة:بدوناسمالمطبعة, بrع اهـ

دهلان, رحمت."Impresi nazhir Terhadap Wakaf Uangal Ekonomi Islam dan Filantropi ,"Ima Islam

$$
\text { الرافعي.العزيزشح الوجيز المعروف بالشرح الكبير. بيروت: دار الكتب العلمية, 1417هـ. }
$$

فريق التحرير:Kompilasi Hukum Islam Edisi Lengkap, Nuansa Aulia, باندونغ:CV. Nuansa Aulia, .2020

$$
\text { القرطبي.المفهم لما أشكل من تلخيص كتاب مسلم.بيروت: دار ابن كثير، IV I I اهـ }
$$

محمود، أسحادي, وإكا رتناساري."تأثير الأجرة على أداء العامل في قسم الإنتاج في شركة UniplastindoInterbuana

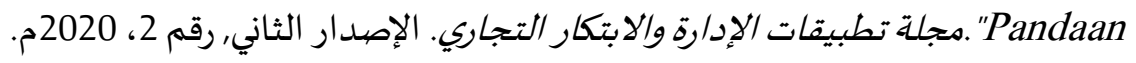

$$
\text { النيسابوري، مسلم بن الحجاج.الجامع الصحيح. بيروت: دار إحياء التراث العربي, بدون السنة. }
$$

وزارة الشؤون الدينية.Proses Lahirnya Undang-undang no. 41 Tahun 2004 Tentang Wakaf.بدون اسم المدينة:المديرية العامة لتوجياه المجتمع الإسلامي وتنفيذ الحج, 2005.

يوليانشاه، وسوفاردي، وفوفوت."تأثير الأجرة على انضباط العامل في عمله في مؤسسة ضمان جودة التربية بسومطرة

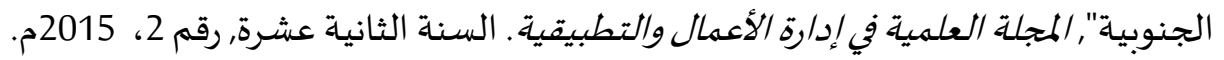


p-ISSN: 2339-2630

Irsan, Erwandi Tarmizi, Hendri Tanjung, e-ISSN: $2477-8001$ الوقف عند الإمام النووي الثافعي

بدون اسم المؤلف، Pelaksanaan Undang-undang Wakaf no.41 Tahun 2004 di Kecamatan Gebang Kabupaten Langkat 